\section{Designing better solar cookers}

SIR - In their Commentary on solar cooking $^{1}$, Kammen and Lankford gave pride of place to the box-type cooker. But this design suffers from several drawbacks, not least that such cookers require cooking to be done in direct sunlight and during the middle of the day, and that they lack storage facilities and have no provision for frying.

In a bid to overcome some of these problems, a cooker with fresnel lens was designed $^{2}$. A large fresnel lens is used to heat a container surrounded by an annular cavity filled with ammoniated salts of magnesium chloride and calcium chloride. Heat is stored chemically in these compounds and is released on demand at $300^{\circ} \mathrm{C}$.

Another system that has storage but is less expensive than the above, uses heat pipes for parabolic as well as flat-plate collectors ${ }^{3}$. In this arrangement, an evaporator with minimum shading effect is placed at the focus of a solar collector. The energy reaching the evaporator is conveyed rapidly to the condenser end of the heat pipe. The condenser, in the form of a cooking chamber, is located in the shade or inside the kitchen. As the shaded cooking chamber is well insulated, pot losses associated with wind will not arise. This system uses energy from sunshine and will not allow reverse circulation losses, due to its diode-like operation ${ }^{4}$. Because of the unique feature of isothermal operation of heat pipes, temperatures

\section{Olbers' paradox}

$\mathrm{S}_{\mathrm{IR}}$ - At least in a mathematical sense there is yet another solution to Olbers' paradox ${ }^{1}$ : fractals ${ }^{2}$. Fractal structures like Menger's sponge can have infinite surface area but zero volume and show a self-similar, scalingindependent distribution of their points. Suppose galaxies, clusters and higher order superclusters of galaxies (or, more exactly, the total mass energy including dark matter) would be distributed in such or a similar fractal fashion. Due to the fractal structure bigger volumes have to contain a relatively lower amount of matter and energy. The energy (and thus also radiation) content per volume falls below any given positive boundary only if a sufficiently large total volume is looked at. Even if it should be static, unlimited or eternal, the sky in such a fractal universe remains dark at night. And so, too, does the sky in our own expanding, finite-age Universe, but what about its large-scale structure $^{3}$; are there some underlying fractal properties?

EMBL, Postfach 102209 ,

ThOMAS DandekaR

W-69 Heidelberg, Germany

1. Maddox, J. Nature 349, 363 (1991).

2. Mandelbrot, B. The Fractal Geometry of Nature (Freeman, New York, 1977).

3. Efstathiou, G., Sutherland, W. J.\& Maddox, S. J. Nature 348 , 705-707 (1990) on a flat-plate collector equipped with a heat pipe will be forced to follow the temperatures in the condenser section.

A more recent addition to the solar cooker family is that developed by Mills and his group at the University of Sydney ${ }^{5,6}$. This cooker can do practically anything a gas or electric stove can, and because it includes a small pressurized water vessel, it can also heat water or power a refrigerator. It can make two large family meals on sunny days and can easily be supplemented with conventional fuel on cloudy days. It has no moving parts, makes use of common materials and can fry, bake, boil or steam food. Its hot plate can be placed indoors, and heat storage allows cooking after sundown.

\section{Society of Science for the People,}

A. JAGADEESH

2/210, Nawabpet, Nellore-524002

Andhra Pradesh, India

KAMMEN AND LANKFORD REPLY - Jagadeesh's letter is similar to several that we have received in response to our article ${ }^{1}$. It describes technically sophisticated designs for solar cookers that will achieve higher temperatures than our simple box-cooker. The question is whether they will be used or not.

Not only are the designs technically complex and rather expensive, but one of them uses magnesium chloride and calcium chloride battery salts that could be harmful to livestock or children if the batteries were dumped or broken and the salts consumed.

We strongly support the notion that a diversity of solar and other renewable technology systems is necessary to support energy self-sufficient development, but we feel that Jagadeesh has missed the essential point concerning the ovens. We have found that when the end user (nearly always a woman) makes her own oven, her interest in using it is very high. If someone else makes and donates the oven or significant components (such as ammoniated salt batteries, condensers or pressurized water vessels), her interest is substantially less. For this reason we believe that until solar cooking equipment has become commonplace a design that can be made locally is essential for widespread acceptance of this technology?.

Daniel. M. Kammen

Division of Biology, 216-76,

California Institute of Technology,

Pasadena, California 91125, USA

Department of Physics,

WILLIAM F. LANKFoRD

George Mason University,

Fairfax, Virginia 22030, USA

1. Kammen, D. M. \& Lankford, W. F. Nature 348, 385 (1990) 2. Hall, C. A. etal. in Proc. ISES Congress (eds F. de Winter \& M Cox) 547 (Pergamon, New Delhi, 1980).

3. Kalifa, A. M. A. et al. Appl. Energy 24, 78 (1986).

4. Akyurt, M. Sol. Energy 32. 625-631 (1984).

5. Mills, D. R. et al. Optics Lett. 5, 558 (1980).

6. Mills, D. R. \& Mao, Y. O. Sunworld 11, 44-49 (1987)

7. Kammen, D. M. Natn. geogr. Res. Explor. 7, 3-5 (1991)

\section{Prion infection}

SIR - The finding that the chaperonin heat shock protein 60 (hsp60) catalyses the assembly of further hsp60 molecules ${ }^{1}$ lends weight to the fascinating possibility ${ }^{2}$ that prion infection might be due to self-perpetuating protein-directed changes in topology. Although, as both Carlson et $a l^{2}$ and Weissman ${ }^{3}$ comment, such replicatory topology alteration is unprecedented as a mechanism of infection, the case of hsp60 illustrates that it is not without precedent as a means of protein topology change. The similarity between the suggested mechanism of prion infection and hsp60 activity is perhaps strong enough to suggest that prion protein could be a rogue chaperonin. Further, the hypothesized topology alteration of hsp60 and prion protein suggests that that which replicates need not be nucleic acid.

Laurence D. Hurst

Department of Zoology,

University of Oxford,

South Parks Road,

Oxford OX1 3PS, UK

Department of Plant Sciences,

DaVid HaIG

University of Oxford,

South Parks Road,

Oxford OX1 3RA, UK

\footnotetext{
1. Cheng, M. Y., Hartl, F.-U. \& Horwich, A. L. Nature 348, 455-458 (1990)

2. Cartson, G. A. Hsiao, K., Oesch, B., Westaway, D. \& Prusiner, S. B. Trends Gen. 7, 61-65 (1991)

3. Weissman, C. Nature 349, 569-571 (1991).
}

\section{Neotropical plant diversity}

SIR - We believe that the overwhelming emphasis on lowland forests with regard to tropical conservation and deforestation has diverted attention from certain patterns of neotropical plant species diversity (see for example, refs 1 and 2). Specifically, the northern Andes, a relatively small and highly deforested region, may have a flora as rich or richer than that of the much larger, mostly intact Amazon basin. Areas of the world that contain the greatest diversity of species and face the most immediate threat of destruction should be given priority for conservation and study.

In most groups of organisms, diversity increases from high to low latitudes and from high to low elevations. The lowland Amazon rainforest has become a popular symbol of a beleaguered stronghold containing millions of species, most of them unknown to science. But the Amazon basin is far from the richest region in the neotropics when plants are considered. Other, smaller regions, such as the northern Andes, Central America and the Atlantic coastal forest of Brazil, are comparatively as rich or richer, and are almost completely deforested, whereas the Amazon forest is relatively intact (see table).

There is no published account of all neo- 